\title{
Effects of Elastic Taping Application Added on Conventional Rehabilitation Therapy to Improve Shoulder Pain and Upper Extremity Motor Function on Subacute Phase Stroke Patients with Shoulder Subluxation
}

\author{
Bimo Sutomo $^{1}$, Subagyo², Martha Kurnia Kusumawardani ${ }^{3}$
}

${ }^{1}$ Bimo Sutomo, Resident of Departments of Physical Medicine \& Rehabilitation Universitas Airlangga, dr. Soetomo General Hospital, Surabaya, Indonesia

2 Subagyo, Staff of Departments of Physical Medicine \& Rehabilitation Universitas Airlangga, dr. Soetomo General Hospital, Surabaya, Indonesia

${ }^{3}$ Martha Kurnia Kusumawardani, Staff of Departments of Physical Medicine \& Rehabilitation Universitas Airlangga, dr. Soetomo General Hospital, Surabaya, Indonesia

\begin{abstract}
Introduction: To determine the effect of adding elastic taping to conventional rehabilitation therapy on the improvement of shoulder pain and motor function of the upper limbs in patients with subacute stroke with shoulder subluxation.

Methods: Research subjects who met the inclusion criteria were recruited from medical rehabilitation clinic in RSUD Dr, Soetomo. The total research subjects were 20 people (10 in treatment group and 10 in control group). The parameters were Visual Analoque Scale (VAS) for assessing shoulder pain and Fugl Meyer Assessment (FMA) for assessing motor function in the upper limbs.

Results: There were significant differences before and after therapy for 3 weeks for VAS ( $p$ value $=0.00)$ in the treatment and control groups, there were significant differences in FMA in the treatment group (p value $=0.04)$, there were no significant difference in FMA in the control group ( $\mathrm{p}$ value $=0.06)$. There was no significant difference in changes of VAS ( $p$ value $=0.23$ ) and FMA $(p$ value $=0.32)$ between the treatment and control groups before and after therapy for 3 weeks.

Conclusion: The treatment group and the control group gave the same results on improvement of shoulder pain and motor function of the upper limbs before and after therapy for 3 weeks. There was an improvement in motor function of the upper limbs in the treatment group and there was no improvement in motor function of the upper limbs in the control group before and after therapy for 3 weeks.
\end{abstract}

Keywords: conventional rehabilitation therapy, elastic taping, Fugl Meyer Assessment (FMA), Glenohumeral subluxation (GHS), Hemiplegic shoulder pain (HSP), Visual Analoque Scale (VAS). 


\section{ABSTRAK}

Pendahuluan: Untuk mengetahui pengaruh penambahan elastic tape pada terapi rehabilitasi konvensional terhadap perbaikan nyeri bahu dan fungsi motorik tungkai atas pada pasien stroke subakut dengan subluksasi bahu..

Metode: Subyek penelitian yang memenuhi kriteria inklusi dari klinik rehabilitasi medik RSUD Dr. Soetomo. Subyek penelitian berjumlah 20 orang (10 kelompok perlakuan dan 10 orang kelompok kontrol). Parameternya adalah Visual Analoque Scale (VAS) untuk menilai nyeri bahu dan Fugl Meyer Assessment (FMA) untuk menilai fungsi motorik pada ekstremitas atas.

Hasil: Terdapat perbedaan bermakna sebelum dan sesudah terapi selama 3 minggu untuk VAS ( $p$ value $=0,00)$ pada kelompok perlakuan dan kontrol, terdapat perbedaan FMA yang signifikan pada kelompok perlakuan ( $\mathrm{p}$ value $=0,04)$, tidak ada perbedaan FMA yang signifikan pada kelompok kontrol (nilai $\mathrm{p}=$ $0,06)$. Tidak ada perbedaan bermakna perubahan VAS ( $\mathrm{p}$ value $=0,23)$ dan FMA ( $\mathrm{p}$ value $=0,32$ ) antara kelompok perlakuan dan kontrol sebelum dan sesudah terapi selama 3 minggu.

Kesimpulan: Kelompok perlakuan dan kelompok kontrol memberikan hasil yang sama pada peningkatan nyeri bahu dan fungsi motorik tungkai atas sebelum dan sesudah terapi selama 3 minggu. Ada peningkatan fungsi motorik tungkai atas pada kelompok perlakuan dan tidak ada perbaikan fungsi motorik tungkai atas pada kelompok kontrol sebelum dan sesudah terapi selama 3 minggu.

Kata Kunci: elastic taping, Fugl Meyer Assessment (FMA), Glenohumeral subluxation (GHS), Hemiplegic shoulder pain (HSP), terapi rehabilitasi konvensional, Visual Analoque Scale (VAS).

\section{Correspondent Detail:}

\section{Martha Kurnia Kusumawardani}

Email: marthakurnia@staf.unair.ac.id Staff of Departments of Physical Medicine \& Rehabilitation, Universitas Airlangga, DR. Soetomo General Hospital, Surabaya, Indonesia.

\section{INTRODUCTION}

Stroke causes hemiparesis (weakness on one side of the body), impaired motor control, and changes in sensibility. Impaired motor performance of the upper limbs is a motor control disorder. Disturbance of motor performance on the upper limbs, among others, the movement of the upper limbs is slower, coordination of the upper limbs decreases, and the speed and accuracy of the upper limbs decreases, so that the functional ability of the upper limbs decreases. Several studies have stated that $85 \%$ of stroke patients experienced upper limb disorders but only $11 \%$ of their hand functions improved, This condition caused functional problems 5 years after stroke 
even though about $47-75 \%$ of patients after stroke experience full or partial independence in their daily living activities. ${ }^{1}$

Stroke patients with hemiparesis about $85 \%$ survived, and $55-75 \%$ had functional limitations in the upper limbs ${ }^{2}$.The first month after stroke, functional recovery of the upper limb occurs most rapidly, and 3 months after stroke reaches the normal function of the upper limb about $20 \%$ of patients. ${ }^{3}$ Major impairment that causes disability is weakness of muscle, and is the biggest obstacle to recovery in stroke patients. Fifty-three percent of weak limbs can be disturbed compared to non-dominant hands in healthy individuals. The strength of ipsilateral hand of the lesion decreased by $15 \%{ }^{4}$

Glenohumeral subluxation (GHS) was defined as a palpable gap between the inferior acromion and superior part of the humeral head with more than one finger's width. The prevalence of GHS in stroke hemiplegia ranged from $17 \%$ to $64 \%{ }^{5}$ Glenohumeral joint subluxation is a complication experienced by stroke patients. The reported incidence of shoulder subluxation varied greatly, from $17 \%$ to $81 \%{ }^{6}$ Generally GHS occurs during the first 3 weeks of hemiplegia. ${ }^{5}$

Hemiplegic shoulder pain (HSP) is a common problem in stroke patients. Hemiplegic shoulder pain can occured at the beginning of the first week after stroke, but most often begins in the $8^{\text {th }}$ to 10th week after stroke. Pain is mostly felt during the spastic recovery phase. ${ }^{5}$ The incidence of HSP was around $65-70 \%$ in patients with acute and chronic stroke. The incidence of HSP in the last decade was around $17-37 \%$ in acute phase stroke, and increased to $47 \%$ in chronic phase stroke. ${ }^{7}$ Hemiplegiac shoulder pain causes disability after stroke. The prevalence was $16 \%$ to $80 \%$, since the stroke. ${ }^{8}$ Stroke patients with hemiplegia shoulder pain and shoulder subluxation had a prevalence of around $17 \%$ in the first week and increased around $22 \%$ to $40 \%$ in the $4^{\text {th }}$ to $6^{\text {th }}$ month. ${ }^{9}$ Ultrasonographic studies had found that the incidence of shoulder subluxation and the frequency of shoulder pain were higher in acute stroke patients with poor upper limb motor function. ${ }^{10}$

Significant shoulder pain occured within 6 months after stroke and there was an increased risk of pain in patients with shoulder subluxation. Preventing the development of shoulder subluxation was considered an important part of stroke management and rehabilitation. ${ }^{11}$

The elastic taping method could facilitate or inhibit muscle function, support joint structure, reduce pain and provide proprioceptive feedback to achieve and maintain good body alignment. ${ }^{12}$ The success of the taping depends on two factors. First, evaluate the patient's condition correctly to provide elastic taping to the right tissue. Second, the provision of appropriate taping techniques. ${ }^{13}$

Research using elastic taping in patients with post-stroke dorsiflexor muscle weakness showed an increase in walking speed and stride length on the healthy side of the patient. ${ }^{14}$ A study in 2017 showed that there were no side effects resulting from the use of Elastic Taping, in fact there was an improvement in the ankle-invertor DCR after ET application, although there was no significant difference in the DCR value of the evertorinvertor ankle on both sides, before and after the use of ET in patients with type 2 DM. ${ }^{15}$

One of the goals of patients seeking therapy was 
to regain functional upper limb after stroke. The results had a significant impact on an individual's physical, psychological and emotional wellbeing. These factors would contribute to the functional problems of the upper limb. ${ }^{12}$ Stroke sufferers expected functional return, through the role of the Physical Medicine and Rehabilitation program. The program aimed to achieve the maximum level of functional independence, minimize disability, reintegration into the home, family and community and rebuild a meaningful and satisfying life. This program must be planned for each sufferer and is never the same for every sufferer. ${ }^{16}$

Research Huang etal.in 44 subacute stroke patients who were randomly divided into the kinesiology taping (KT) therapy group and the placebo KT. Both groups received conventional rehabilitation at the hospital 5 times per week for 3 weeks in patients with subacute stroke with hemiplegia. The result was a significant difference ( $p$ value $<0.05$ ) in HSP improvement and improvement in upper limb function (FMA) between the two groups. In conclusion KT therapy could limit the development of HSP in subacute stroke patients with hemiplegia. Kinesiology taping therapy did not provide an increase in upper limb function more than the placebo KT during conventional rehabilitation. ${ }^{17}$

Research Huang et al.about the effect of installing KT for 3 weeks in 21 patients who experienced first stroke and duration of stroke less than 6 months, with shoulder pain on the side of paresis. The study divided the participants into two groups (KT therapy and KT placebo) and both groups were given conventional rehabilitation therapy consisting of exercise and occupational therapy 60 minutes per day, 5 times per week for 3 weeks.
The results showed a significant difference in comparing changes in HSP reduction with numeric rating scale (NRS) before and after 3 weeks of therapy between the two groups ( $p$ value $=0.008)$. There was a reduction in shoulder pain in the KT therapy group compared to the KT placebo. ${ }^{7}$

Based on the data above, the researcher encouraged further studies to be conducted on the effects of applying elastic taping applications on conventional rehabilitation therapy on the improvement of shoulder pain and motor function of upper limbs in patients with subacute stroke stroke with shoulder subluxation. Conventional rehabilitation therapies to be given are physiotherapy and occupational therapy 60 minutes per day, 3 times per week for 3 weeks and installation of elastic taping with elastic taping replacement every 3 days.

Side effects of research that may occur during and after the use of elastic taping is a hypersensitive reaction. Researchers will carry out the procedure of managing the side effects of research if found signs of hypersensitive reactions to elastic taping material.

The diagnosis of glenohumeral subluxation is based largely on clinical examination. Bohannon and colleagues found that shoulder palpation could be assessed accurately in diagnosing shoulder subluxation, with good inter-assessor reliability and correlation with more precise radiographic measurements. ${ }^{18,5}$

The general objective of the study was to determine the effect of the addition of elastic taping application to conventional rehabilitation therapy on the improvement of shoulder pain 
and motor function of the upper limbs in patients with subacute stroke stroke with shoulder subluxation. The benefit of research for health services was to recommend the use of elastic taping and conventional rehabilitation therapy in patients with subacute stroke stroke with shoulder subluxation in the paresis as an effort to reduce shoulder pain and improve motor function of the upper limbs if the results of the study are good.

\section{RESEARCH METHODS}

Pre-control randomized design experimental study with different participants to compare the effects of elastic taping (treatment group) and non-elastic taping (control group) in 20 stroke patients with subacute shoulder pain and shoulder subluxation in the two groups that received conventional rehabilitation training (physiotherapy and occupational therapy), 60 minutes per day, 3 times per week for 3 weeks. Subjects in the treatment group were given additional elastic taping to the shoulder of the paresis with elastic taping replacement every 3 days, for 3 weeks. The skin was checked each time elastic taping was removed to see changes in skin integrity and rashes or allergies due to the installation of elastic taping.

The elastic taping method in this study aims to activate neuromuscular function and produce shoulder mechanical support. Taping used was $5 \mathrm{~cm}$ wide. Facilitation techniques are used for deltoid, supraspinatus, and teres minor muscles. ${ }^{19}$

1. The supraspinatus muscle was taped by means of the shoulder being positioned in an abduction position of about 30 degrees with a slight flexion and internal rotation, and the humeral head was positioned back to its normal place. The first $4 \mathrm{~cm}$ of the strip was applied to the origo supraspinatus (medial superior scapular border) without strain. Then, the remaining strip was applied over the insertion site of the muscle (major humerus tubercles) with a stretch of about 25$50 \%$ of the full stretch.

2. After that, the patient's shoulder was abducted 30 degrees. Taping in the middle of the deltoid muscle begins by attaching the first $4 \mathrm{~cm}$ strips above the acromion process without strain. Then, the remaining strips are stretched under the deltoid tuberosity with a $20-30 \%$ strain.

3. Taping teres minor, shoulders flexed with a little internal flexion. The base of the strip was placed at the scapular inferior angle. The remaining strips were stretched with a stretch of $15-25 \%$ and placed along the axillary border of the scapula to the major tuberosity of the humerus.

4. The final taping was used to reduce shoulder subluxation and cut it into a $\mathrm{Y}$ shape before sticking it. After repositioning the shoulder, the base of the strip was applied to the acromion process, and then, both ends of the strip are stretched with 50-70\% strain and placed along the deltoid anterior and posterior borders separately to the deltoid tuberosity.

Inclusion Criteria:

a. Hemiplegia subject with sub acute phase stroke with shoulder pain and shoulder subluxation, Manual muscle testing (MMT) is less than 3 .

b. Shoulder pain on the hemiplegi side was measured using a VAS (Visual Analoque Scale) value, of at least $40 \mathrm{~mm}$ (moderate pain) based on clinical examination. 
c. Subjects can understand and follow examination instructions [Mini-mental state examination (MMSE) score 24-30].

d. Subjects participated in a comprehensive comprehensive rehabilitation program of 60 minutes per day, 3 times per week for 3 weeks.

e. Subjects were willing to become research subjects by signing an informed consent form after obtaining an explanation as in Appendix 1 (information sheet for the subject).

\section{Exclusion Criteria:}

a. A history of fracture of the clavicle, acromion, glenoid fossa or humerus is less than 1 year and unstability of the side of the weak upper limbs or a history of shoulder sprain or subluxation before stroke.

b. Acute inflammation of the shoulder area.

c. Lesions on the skin of the shoulder or the area to be installed elastic taping.

d. Subjects received elastic taping therapy on the shoulder area of the paresis side within the previous 5 days.

e. Subjects used arm slings or axillary roll, or both for hemiplegica shoulder subluxation therapy.

The criteria for dropping out were hypersensitivity to elastic taping material and subject was not willing to continue the research interventions or the subject did not come in the conventional rehabilitation programs 3 times in a row.

Subacromion gap measurement was determined by the subject sitting in an upright posture without a backrest or in an armchair, with arms in a neutral position depending on the side of the body. Shoulder subluxation was examined by marked presence of a sulcus sign on the weak shoulder with palpation of the examiner's index finger and measured using a measuring tape. Shoulder subluxation was of at least $5 \mathrm{~mm}$ (0.2 inches) in the affected upper extremity. ${ }^{20}$

Subjects who had met the inclusion criteria were given an explanation of the aims, objectives and procedures of the study. If the subject was willing, then the subject was asked to sign the consent form to be the research subject of the medical action consent sheet and the research subject data was collected.

The study subjects were divided randomly into 2 groups, then a physical examination was conducted. Examination of pain in the subluxated shoulder was done using VAS in stationary position with the anatomical position of the shoulder (forearm supination) and during movement of the subluxated shoulder through its range of motion. Clinical examination was carried out in standing or upright sitting position without using support on hemiplegic upper limbs with good trunk control. VAS value of at least $40 \mathrm{~mm}$ (moderate pain) and the greatest VAS value were used for data analysis. Initial VAS and FMA (Fugl Meyer Assessment) tests were carried out before getting conventional rehabilitation therapy in both groups and without placing elastic taping in the treatment group, then elastic taping was placed. Final VAS examination was carried out after receiving conventional rehabilitation therapy in both groups. Final VAS and FMA examination was performed after the elastic taping was removed in the treatment group. Data analysis was performed by comparing the results of VAS and FMA examination of upper 
limb hemiplegia, before and after conventional rehabilitation therapy in both groups and the installation of elastic taping in the treatment group for 3 weeks.

Statistical tests were performed using SPSS software version 20.0. The normality tests of VAS score and FMA examination data were performed using the Shapiro-Wilks test before statistical analysis. Parametric statistical tests are used for statistical analysis when the measurement results are normally distributed. Paired $t$ test was used for VAS and FMA examination in group analysis. Significant differences between groups of data from VAS and FMA examination occurred at $\mathrm{p}<0.05$ with $95 \%$ confidence intervals calculation.

\section{RESULT}

Conventional rehabilitation therapy was given at the clinic. All subjects followed the study to completion. No side effects were found during the study when using elastic taping and following a conventional rehabilitation program.

The parameters evaluated in this study were shoulder pain which was assessed by the VAS value and motor function of the upper limbs which was assessed by the FMA score on the paresis side. This examination was carried out twice, namely at the beginning of the study (before conventional rehabilitation therapy alone in the control group; conventional rehabilitation therapy plus elastic taping in the treatment group) and at the end of the study.
The total subjects of this study were 20 people, divided into two groups (treatment and control) with a total of 10 subjects in each group. Each group consisted of 8 men and 2 women. All research subjects in the treatment and control group could complete the study until the end.

The number of subjects in this study were 20 people who were divided into two groups, namely treatment and control. The number of subjects in this study were 10 people in the treatment group and 10 people in the control group. Data normality was tested using Saphiro-wilk. Homogeneity test results of the two groups (Table 1) showed no significant differences, so it could be concluded that the data of both groups were homogeneous.

The number of subjects according to sex in each group was equal, namely 8 men and 2 women. The types of stroke in each group were the same, namely 9 people with infarct stroke and 1 person with bleeding stroke. The frequency of stroke attacks in each group was different, namely the first stroke of 9 people, the second stroke of 1 person in the treatment group and the first time of 8 people, the second stroke of 2 people in the control group. The number of subjects of the paresis side was the same in each group, namely the right side of 4 people, the left side of 6 people. Risk factors owned by the subject, namely history: 4 people hypertension; diabetes mellitus (DM) 2 people; dyslipidemia 3 people; smoking 6 people in the treatment group and history: 9 hypertension; diabetes mellitus 2 people; dyslipidemia 1 person; smoked 2 people in the control group. 
Table 1. Test the homogeneity of the initial characteristics of research subjects

\begin{tabular}{lccc}
\hline \multicolumn{1}{c}{ Variable } & Treatment (n=10) & Control (n=10) & P Value \\
\hline Age (year) & $55,40 \pm 12,21$ & $57,60 \pm 6,81$ & 0,63 \\
BMI (kg/m2) & $23,39 \pm 3,79$ & $22,97 \pm 3,32$ & 0,79 \\
Stroke Duration (week) & $8,60 \pm 8,05$ & $14,60 \pm 8,78$ & 0,17 \\
VAS-Before (mm) & $53,00 \pm 12,51$ & $62,00 \pm 16,19$ & 0,18 \\
FMA-Before & $15,00 \pm 11,09$ & $14,50 \pm 9,52$ & \\
Gender: & & & \\
Male & $8(80 \%)$ & $8(80 \%)$ & \\
Female & $2(20 \%)$ & $2(20 \%)$ & \\
Stroke Type: & & $9(90 \%)$ & \\
Infarct & $9(90 \%)$ & $1(10 \%)$ & \\
Hemorrhagic & $1(10 \%)$ & & \\
Stroke Frequency: & & $8(80 \%)$ & \\
First Time & $9(90 \%)$ & $2(20 \%)$ & \\
Second Time & $1(10 \%)$ & $4(14,14 \%)$ & \\
Paresis Side: & & $6(60 \%)$ & \\
Right & $4(40 \%)$ & & \\
Left & $6(60 \%)$ & & \\
Risk Factor: & $4(26,67 \%)$ & & \\
Hipertensi & $(13,33 \%)$ & & \\
Diabetes melitus & $3(20 \%)$ & & \\
Dislipidemia & $6(40 \%)$ & & \\
Smoking History & & & \\
\hline
\end{tabular}

* Homogeneity test is significant if the $\mathrm{p}$ value $<0.05$.

Table 2. VAS values before and after in both groups

\begin{tabular}{ccccccc}
\hline \multirow{2}{*}{ Variable } & \multicolumn{2}{c}{ Treatment $(\mathbf{n}=\mathbf{1 0})$} & \multicolumn{3}{c}{ Control $(\mathbf{n}=\mathbf{1 0})$} \\
& Before & After & P Value & Before & After & P Value \\
\hline VAS & $53,00 \pm 12,51$ & $20,00+9,42$ & $0.00^{*}$ & $62,00 \pm 16,19$ & $22,00+11,35$ & $0.00^{* *}$ \\
\hline
\end{tabular}

* VAS : Visual Analoque Scale, Independent samples T test is significant if the p value $<0.05$. 
Table 3. FMA scores before and after in both groups

\begin{tabular}{ccccccc}
\hline \multirow{2}{*}{ Variable } & \multicolumn{3}{c}{ Treatment $(\mathbf{n}=\mathbf{1 0})$} & \multicolumn{3}{c}{ Control $(\mathbf{n}=10)$} \\
& Before & After & P Value & Before & After & P Value \\
\hline FMA & $15,00+11,09$ & $26.20+17,89$ & $0,04^{*}$ & $14,50+9,52$ & $16,70+9,85$ & 0.06 \\
\hline
\end{tabular}

* FMA : Fugl Meyer Assessment, The Wilcoxon signed ranks test is significant if the p value $<0.05$.

Table 4. Comparison of reduction in VAS difference in the two groups

\begin{tabular}{cccc}
\hline Variable & Treatment $(\mathbf{n}=\mathbf{1 0})$ & Control $(\mathbf{n}=\mathbf{1 0})$ & P Value \\
\hline VAS & $33,00+9,49$ & $41,00+17.92$ & 0,23 \\
\hline
\end{tabular}

* VAS : Visual Analoque Scale, Independent samples T test is significant if the p value $<0.05$.

Table 5. Comparison of the increase in the difference in FMA scores in the two groups

\begin{tabular}{cccc}
\hline Variable & Treatment $(\mathbf{n}=\mathbf{1 0})$ & Control $(\mathbf{n}=\mathbf{1 0})$ & P Value \\
\hline FMA & $11.20+17,43$ & $2,20+3,70$ & 0.32 \\
\hline
\end{tabular}

* FMA : Fugl Meyer Assessment, The Mann-Whitney test is significant if the p value $<0.05$

Table 2 shows that there were significant differences in the VAS values before and after therapy for 3 weeks in the treatment and control groups with $p=0.00$.

Table 3 shows that there was a significant difference in the FMA score in the treatment group with a value of $p=0.04$ and there was no significant difference in the FMA score in the control group with a value of $p=0.06$, before and after therapy for 3 weeks.

Table 4 shows that there was no significant difference in the decrese of in VAS values between the two groups with a value of $p=0.23$.

Table 5 shows that there was no significant difference in the comparison of the increase in the difference in FMA scores between the two groups with a value of $p=0.32$.

\section{DISCUSSION}

There were significant differences in VAS score in the two groups before and after therapy $(\mathrm{p}=$ 0.00 ) in each group. This shows that there was significant improvement in shoulder pain in both groups before and after therapy for 3 weeks.

The results of improved VAS in both groups in this study were consistent with the research of Yang et al. (2018) which showed that there was a significant difference in the intensity of shoulder pain with the numerical pain rating scale (NPRS) in the treatment group ( $\mathrm{p}$ value $<0.05$ ) and control ( $\mathrm{p}$ value $<0.05$ ) after the installation of kinesio taping (KT) and administration of 60 minutes of physiotherapy, 20 minutes of electrostimulation therapy, 5 times per week for 4 weeks in 19 stroke patients with stroke duration of more than 1 month and less than 6 months. Both groups were 
paired with KT (KT therapy with tension in the treatment group and placebo KT without stress on control) in the same muscle with facilitation techniques, and KT was installed for 10 to 12 hours per day. ${ }^{19}$

The results of improved VAS in both groups in this study were in accordance with the research of Chatterjee et al. (2015) which showed that taping using the California tri-pull taping (CTPT) method can produce a significant reduction in shoulder pain $(p=0,000)$ on the VAS scale before and after treatment in 10 acute stroke patients. Treatment with taping was changed every Monday, Wednesday, Friday per week and gets a 45-minute neuroconventional rehabilitation program per day, 5 times per week for 6 weeks. Taping technique with inhibition technique. Cotton-covered taping then rigid taping on it with a rigid strip with a strong pull up. ${ }^{21}$

The results of improved VAS in both groups in this study were in accordance with the research of Huang et al. (2017) which showed that there were significant differences in changes in HSP reduction with a numerical rating scale (NRS) before and after 3 weeks of therapy in the treatment group (KT therapy) (p value $<0.001$ ) and control (KT placebo) (p value $<0.001)$. The number of subjects was 21 patients who had their first stroke with a duration of stroke less than 6 months. Both groups were fitted with $\mathrm{KT}$ and given physiotherapy and occupational therapy 60 minutes per day, 5 times per week, for 3 weeks. Konesiotaping in both groups was removed for 24 hours after taping for 3 days, the taping technique used the same muscle inhibition and correction of space in the joints with certain stresses in the treatment group and without tension in the control, using KT Nitto Denko from Osaka, Japan. ${ }^{7}$
The results of the improvement of the VAS of the two groups in this study were not in accordance with the study of Pillastrini et al. (2015) that showed significant differences in the VAS variables in the treatment group ( $p$ value $<0.05$ ) and no significant differences in the control group ( $\mathrm{p}$ value $>0.05$ ) before and after 4 weeks of therapy. The treatment group received the application of neuromuscular taping (NMT) in certain muscles, with changes every 5 days and the standard physical therapy program (SPTP), while the control group only received SPTP. All groups of ischemic stroke patients received SPTP 45 minutes for 4 weeks. Number of subjects 31 people. The duration of the stroke was 3.1 years in the treatment group and 2.9 years in the control. The taping technique used is the technique of inhibition and is applied without tension with the muscles in the stretched position. ${ }^{22}$

The results of the improvement of the VAS of the two groups in this study were not in accordance with the research of Chatterjee et al. (2016) that showed no significant difference ( $p$ value $>0.05$ ) in the VAS variable in the control group (not given taping) in acute stroke patients after 6 weeks of therapy. The number of samples is 30 people. Taping method with inhibition technique, using 2 types of strips, cotton-covered adhesive strips and rigid adhesive strips. This cotton-covered strip was then applied to the same location as the stiff strip but with a strong pull up. ${ }^{20}$

The results of the improvement of the VAS of the two groups in this study were not in accordance with the research of Heo et al. (2015) that showed no significant differences in shoulder pain (VAS) after 4 weeks of therapy in both groups of acute stroke patients. Significant value $(p=0.05)$. The treatment group received physical therapy in 
bed and inelastic taping and the control group only received physical therapy in bed. Physical therapy was carried out in the intensive care unit (ICU). The number of samples 36 people. The taping method used was by placing inelastic strips on the front and back sides of the supraspinatus, pectoralis and sternal pectoralis major part of the middle after correcting shoulder subluxation, taping is used inelastic. ${ }^{23}$

The improvement in VAS may have been caused by several theories about shoulder pain after stroke. Shoulder pain after stroke can be prevented, among others, by range of motion exercises. ${ }^{24}$ Early physical therapy is important for preventing pain. ${ }^{23}$ The correct position and alignment of the body will reduce shoulder pain and passive range of motion exercises on the hemiplegic shoulder help improvinge motor function9. The elastic taping method can facilitate or inhibit muscle function, support joint structure, reduce pain and provide proprioceptive feedback to achieve and maintain correct body alignment. ${ }^{12}$ Taping improves alignment, serves as a reminder for patients to correct the position of AGA correctly, preventing stretching of weak rotator cuff muscles and other soft tissues. ${ }^{9}$ Taping has an effect on sensorimotor. ${ }^{12,25}$

The taping effect can change muscle function in weak muscles by supporting and reducing increased muscle tone, improving blood and lymph circulation by removing tissue fluid or bleeding under the skin, reducing pain through nerve compression, repositioning joint subluxation by reducing abnormal muscle tension, helps influence fascia and muscle function, and increases joint proprioception through increased stimulation of skin mechanoreceptors. ${ }^{26,27}$
There was a significant difference in the FMA score before and after therapy with a $\mathrm{p}$ value 0.04 in the treatment group, this indicates that there was a significant improvement in the motor function scores of the upper limbs (FMA) in the treatment group, but in the control group there was no difference which was significant in the FMA score before and after therapy with a $p$ value $=0.06$, this showed that there was no significant improvement in the motor function scores of the upper limbs in the control group before and after therapy for 3 weeks.

The results of improved FMA treatment groups in this study are in accordance with the research of Chatterjee et al. (2015) which showed that tapping using the California tri-pull taping (CTPT) method could result in a significant increase in motor function ( $\mathrm{p}$ value $=0,000$ ) on the Fuglmeyer scale (FUG) before and after treatment in one group (10 people) of acute stroke patients during 6 weeks. The treatment with the installation of taping was changed every Monday, Wednesday, Friday per week and received a neuroconventional rehabilitation program 45 minutes per day, 5 times per week for 6 weeks. ${ }^{21}$

The results of the improved FMA of the two groups in this study were not in accordance with the research of Huang et al. (2019) that showed a significant increase with $\mathrm{p}<0.01$ in FMA of proximal limbs $(\mathrm{p}=0.001)$ and distal $(\mathrm{p}=0.001)$ in the treatment group; FMA of proximal upper limbs $(\mathrm{p}$ value $=0.019)$ and distal $(\mathrm{p}$ value $=$ $0.004)$ in the control group after 3 weeks. The treatment group was installed KT 7 days per week for 3 weeks and the control was not installed KT, but both groups received occupational therapy and rehabilitation exercises 2 sessions, 20 minutes per session, 2 times per day, 5 days 
per week for 3 weeks. The results KT could improve performance on the paresis of the limbs of subacute stroke patients with stroke duration of 6 months. ${ }^{28}$

The results of the improvement in the FMA of the two groups in this study were not in accordance with those of Chatterjee et al. (2016) that showed a significant difference ( $p$ value $<0.01$ ) in the variables FMA-P, FMA-D, FMA-T in the control group (not given taping) in acute stroke patients after 6 weeks of therapy. ${ }^{20}$

The difference in the results of improvement in the FMA score in the two groups could be caused by the different treatment duration compared to other studies, the lack of improvement in the FMA score in the control group could be caused by the longer the stroke of the control group than the treatment group, even though after being tested for homogeneity it was declared insignificant. The average stroke duration of the treatment group was 8.6 weeks while the control group was 14.6 weeks (stroke in the control group took 6 weeks longer than the treatment group), because the longer the stroke, the prognosis would improve function. If correlated between stroke duration with FMA score before: The stroke duration variable in the treatment group was shorter ( 8 weeks) but the FMA score was the same, even slightly better (15 vs 14.5 ) compared to the control group (14 weeks) and the attack variable the second stroke in the control group was slightly more than the treatment (2 vs 1 ), so that the prognosis for improvement of upper limb motor function in the treatment group was better than the control.

The relationship between type of stroke, duration of stroke and prognosis of stroke was found in the research of Sennfält et al. (2018) showed that 2 out of 3 patients in infarct stroke (IS), and 3 out of 4 patients in intracerebral hemorrhage (ICH) stroke, died or were functionally dependent, early mortality was higher in ICH than IS in 5 years after stroke, whereas in for more than 30 days, survival decreases at the same rate for both types of stroke. The proportion of functional patients dependent on survivors was less favorable at ICH compared to IS at all time points. There has been significant progress in the care and rehabilitation of longterm stroke in the last few decades, but there was a need for further improvements in meeting future needs. The functional results were lacking in ICH which is followed for 3 months or 12 months. Poor outcomes (death or functional dependent) are $79 \%$ in ICH and $70.6 \%$ in IS within 5 years. ${ }^{29}$ ICH stroke and long stroke duration provided less functional dependent prognosis than IS stroke.

Patients with recurrent stroke have larger lesions, more severe strokes, and much higher mortality rate than the first stroke. Neurological recovery was no different in recurrent stroke in contralateral and ipsilateral lesions. Worse recovery and decreased functional ability in recurrent stroke patients with contralateral lesions. Patients with recurrent stroke have more severe brain lesions and worse sensorimotor function than the first stroke. $^{30}$

Twenty to thirty percent of stroke cases will have repeated stroke attacks. The risk of repeated stroke 9 to 15 times greater than the first attack on populations of the same age and sex. The mortality of patients with recurrent stroke attacks is two times greater than that of patients with first stroke attacks. If recurrent stroke affects the contralateral brain hemisphere, the patient will experience a very severe functional disability compared to if 
only affected in one brain hemisphere. The ability of functional compensation decreases when it affects both hemispheres of the brain. ${ }^{31}$

Research Kim et al. (2014) aims to determine the correlation between Activities of daily living (ADL) and quality of life (QOL) in 68 chronic stroke patients. Three questionnaires were distributed by visiting the subject (general research subject information, stroke-specific QOL (SS-QOL) and functional independence measure (FIM). The results of all items and the total FIM score showed a high correlation with the total QOL score. The relationship between ADL and Total QOL scores show significant positive correlations, FIM variables, mobility and social cognition show the most significant effects and have the greatest effect on total QOL scores. ${ }^{32}$

The improvement in FMA may have been caused by several theories about impaired AGA motor function after stroke. Functional disorders of the upper limb occur when one of the many components of the scapula and shoulder (including all four articulations) malfunctions. ${ }^{12}$ Shoulder subluxation will limit LGS and may inhibit functional recovery. ${ }^{12,5}$ Shoulder subluxation does not provide a stable basis for correcting or enhancing upper limb control and relating to poor upper limb function. ${ }^{5}$ Shoulder subluxation can have a negative effect on the recovery of motor function11. Shoulder subluxation has a negative effect on functional recovery after stroke, activity and quality of daily life. ${ }^{9}$

Taping is a therapeutic method used to treat various musculoskeletal and neuromuscular deficits. ${ }^{12,25}$ Elastic taping can improve LGS and motor performance in stroke patients. ${ }^{33,22}$ Taping can reduce mechanical retention and movement limitations. Taping has an effect on facilitating muscle activation and increasing blood and lymph circulation. ${ }^{34}$

Taping could be used as an adjunct during rehabilitation programs to improve functional recovery by increasing alignment, and stimulating muscle function, helping support muscle function and joint structure, and reducing soft tissue inflammation. Taping is used to help maintain shoulder girdle stability. ${ }^{12,25}$ Taping can activate neuromuscular function, which is very important for the recovery of motor function in patients after stroke. ${ }^{19}$ Stimulating the sensorimotor system to achieve normal and functional voluntary movements in the upper limb is included in the rehabilitation program. ${ }^{12}$

The average difference in the value of VAS in the treatment group $(33 \mathrm{~mm})$ was smaller than the control (41 mm), so the improvement of shoulder pain in the treatment group was better than the control (the average difference between the two groups $=8 \mathrm{~mm}$ ), but statistically the result was no significant difference in the difference in the difference in VAS between the two groups with a value of $p=0.23$ before and after therapy for 3 weeks.

The results of the VAS comparison between the two groups in this study were in accordance with the research of Hanger et al. (2000) that found no significant difference in VAS $(\mathrm{p}=0.11)$ between the treatment (taping) and control (no taping) groups after 6 weeks of therapy in patients with acute hemiplegia stroke. Number of subjects 98 people. The taping technique uses the technique of space inhibition and correction consisting of 3 long strips without tension (Elastoplast Sports tape) applied over the 'undertape' (Hypafix) to 
prevent skin reactions. The treatment group used taping, taping replacement every 2 to 3 days (maximum 3 days) and both groups received standard physiotherapy for 6 weeks. ${ }^{8}$

The results of the VAS comparison between the two groups in this study were not in accordance with the research of Yang et al. (2018) which showed a significant difference in the intensity of shoulder pain (NPRS) between the treatment and control groups $(\mathrm{p}$ value $=0,000)$ after 60 minutes of exercise therapy, 20 minutes of electrostimulation therapy, 5 times per week, for 4 weeks in more stroke patients than 1 month and less than 6 months. ${ }^{19}$

The results of the VAS comparison between the two groups in this study were not in accordance with the study of Pillastrini et al. (2015) that showed significant difference in the VAS variables between the treatment and control groups ( $p$ value $<0.05$ ) after 4 weeks of therapy. The treatment group received the application of neuromuscular taping (NMT) 15 minutes of persistence in certain muscles with replacement every 5 days and the standard physical therapy program (SPTP), while the control group only received SPTP. Ischemic stroke patients receive SPTP 45 minutes per session, 4 sessions for 4 weeks. ${ }^{22}$

The results of the VAS comparison between the two groups in this study were not in accordance with the research of Griffin and Bernhardt (2006) that found significant differences $(\mathrm{p}$ value $=0.023$ ) of the average number of pain-free days measured using the Ritchie Articular Index during a 28-day period between treatment and control group. All three groups received physiotherapy and standard occupational therapy. There were 32 subjects in the treatment group (taping therapy), placebo taping, and control (without taping). The taping technique used was facilitation technique. The taping used is a $5-\mathrm{cm}$ Fixamull, replaced every 3 to 4 days for 4 weeks. ${ }^{35}$

The results of the VAS comparison between the two groups in this study were not in accordance with the research of Chatterjee et al. (2016) that showed a significant difference ( $p$ value $<0.05$ ) in the variable VAS (reduction of shoulder pain) between the treatment and control groups in acute stroke patients. The treatment group was given taping by the California tri-pull taping (CTPT) method and the control group was not given taping. Taping is changed every Monday, Wednesday, and Friday every week, for 6 weeks. Both groups were given conventional neurorehabilitation 45 minutes per day, 5 times per week for 6 weeks. ${ }^{20}$

The results of the VAS comparison between the two groups in this study were not in accordance with the research of Huang et al. (2017) that showed a significant difference in comparing changes in HSP reduction with NRS before and after 3 weeks of therapy between the treatment (KT therapy) and control (KT placebo) groups with a $p$ value of 0.008 in patients who first had strokes with less stroke duration than 6 months. Number of subjects 21 people. Both groups received physiotherapy and occupational therapy, 60 minutes per day, 5 times per week, for 3 weeks and free taping 24 hours after tapping for 3 days. $^{7}$

This shows that both conventional rehabilitation therapy and with the addition of elastic tapping there was no significant difference related to decreased VAS. So it could be concluded that giving elastic tapping did not provide additional 
benefits to decrease shoulder pain after stroke in this study.

Variable average FMA score difference in the treatment group (11.20) was greater than in the control group (2.20), so improvement in upper limb motor function in the treatment group was better than the control (average difference between the two groups $=9$ ), but statistically the results showed no significant differences in the increase in the difference in FMA scores between the two groups with $p=0.32$ before and after therapy for 3 weeks.

The results of this study were in accordance with the research of Huang et al. (2019) which showed that there were no significant differences in the proximal limb FMA ( $p$ value $=0.057)$ and distal $(\mathrm{p}$ value $=0.574)$ in the third week between treatment groups (KT replacement for 7 days per week for 3 weeks) and control (not mounted KT) in subacute stroke patients (6 month stroke duration) for 3 weeks. Kinesiotaping can improve performance on the paresis of the limbs over subacute stroke patients. Both groups received occupational rehabilitation therapy 20 minutes per session, 2 times per day, 5 days per week for 3 weeks. Number of subjects 31 people. Kinesiotape used by Nitto Kogyo Corporation. The taping technique used was a facilitation technique with a certain stress. $^{28}$

This result was not in accordance with the research of Subhasish Chatterjee et al. (2016) showed a significant difference in the FMA-proximal variable ( $p$ value $<0.05)$ from the comparison between the treatment and control groups in acute stroke patients after 6 weeks of therapy. ${ }^{20}$
Changes in FMA in the treatment and control groups were not significant but there was a greater increase in the treatment group, this shows that the addition of elastic taping to conventional rehabilitation therapy would increase the effectiveness of therapy to produce results in improvement of upper limb motor function. No side effects in the study occurred during and after the use of elastic bands.

\section{Benefits of Research Findings}

Therapy by placing elastic taping on the shoulder of the paresis side and conventional rehabilitation with physiotherapy and occupational therapy was another form of treatment of rehabilitation therapy that had the effect of reducing shoulder pain and improving motor function of the upper limbs in patients in subacute phase stroke with shoulder subluxation. Giving conventional rehabilitation therapy alone, had given good results in terms of repairing shoulder pain without the addition of elastic taping, but in terms of improving the motor function of the upper limbs, the addition of elastic taping would give better results.

\section{Research Limitations}

Limitations of this study include:

The type of therapy given in this study was not possible to be done in disguise (blinded), so the research subjects were aware of the type of therapy given.

Evaluation of research results after the therapy was carried out by the researchers themselves, not done in disguise, so that it could lead to measurement bias that was examiner bias.

The motivation and enthusiasm of each research subject was not assessed.

The research subjects could not come to the hospital because of the Corona virus pandemic. 


\section{CONCLUSION}

There was improvement in shoulder pain in the treatment group (conventional rehabilitation therapy and elastic taping) and controls (conventional rehabilitation therapy only) before and after therapy for 3 weeks.

There was an improvement in the motor function of the upper limbs in the treatment group and there was no improvement in the motor function of the upper limbs in the control group before and after therapy for 3 weeks.

The treatment and control groups gave the same results for improvement of shoulder pain before and after therapy for 3 weeks.

The treatment and control groups gave the same results to the improvement of motor function of the upper limbs before and after therapy for 3 weeks.

Adding elastic taping application (replacing elastic tapng every 3 days) to conventional rehabilitation therapy (60 minutes per day, 3 times per week) for 3 weeks can be considered as a therapy to reduce shoulder pain and improve motor function of the upper limbs in patients with subacute phase stroke with shoulder subluxation.

Further research needs to be conducted to evaluate the effect of adding elastic taping applications to conventional rehabilitation therapy on the improvement of shoulder pain and limb motor function in patients with subacute stroke stroke with shoulder subluxation in a larger sample size, subject age is restricted, frequency of stroke attacks is limited, stroke duration is limited.

\section{REFERENCE}

1. Sciusco, A., Ditrenta, G., A. Rahinò, S. Damiani, M. Megna, M. Ranieri and G. Megna 2008. Mirror therapy in the motor recovery of upper extremity. Europa Medicophysica. Vol. 44. Pp. 1-4.

2. Yavuzer, G., Selles, R., Sezer, N., Sutbeyaz, S., Bussmann, J.B. and Kaseoglu, F. 2008. Mirror therapy improves hand function in subacute strok: a randomized controlled trial. Archives of physical medicine and rehabilitation. 89(3): 393-8.

3. Hara, Y. 2013. Rehabilitation with functional electrical stimulation in strok patients. International Journal of Physical Medicine and Rehabilitation. 1: 6-8.

4. Blanton, S. and Wolf, S.L. 2006. Arm and hand weakness. Textbook of Neural Repair and Rehabilitation. Cambridge: Cambridge University Press. Pp. 265-82.

5. Stolzenberg, D., Siu, G. and Cruz, E. 2012. Current and Future Interventions for Glenohumeral Subluxation in Hemiplegia Secondary to Strok, Topic in Strok Rehabilitation. Vol. 19, No. 5, Pp. 444-456.

6. Linn, S.L., Granat, M.H., and Lees, K.R., 1999. Prevention of shoulder subluxation after strok with electrical stimulation. Strok. 30: 963-968.

7. Huang, Y.C., Chang, K.H., Liou, T.H., Cheng, C.W., Lin, L.F. and Huang, S.W. 2017. Effects of kinesio taping for strok patients with hemiplegic shoulder pain: A doubleblind, randomized, placebo-controlled study. J Rehabil Med; Taiwan. 49: Pp. 208-215.

8. Hanger, H.C., Whitewood, P., Brown, G., Ball, M.C., Harper, J., Cox, R. and Sainsbury, R. 2000. A randomized controlled trial of 
strapping to prevent post-strok shoulder pain. Clin Rehabil. 14(4): Pp. 370-380.

9. Ravichandran,H., Janakiraman, B., Sundaram, S., Fisseha, B., Gebreyesus and Gelaw, A.Y. 2019. Systematic Review on Effectiveness of shoulder taping in Hemiplegia. Journal of Strok and Cerebrovascular Diseases. Ethiopia. Pp. 1-11.

10. Huang, Y.C., Liang, P.J., Pong, Y.P., Leong, C.P. and Tseng, C.H. 2010. Physical findings and sonography of hemiplegic shoulder in patients after acute strok during rehabilitation. J Rehabil Med. 42: Pp. 21-26.

11. Razaq, S. and Rathore, F.A. 2016. An Overview of Pathophysiology,

12. Assessment and Management Strategies of Post Strok Shoulder Subluxation,Pakistan Journal of Neurological Sciences. Vol. 11, No. 3, Pp. 42-48.

13. Jaraczewska, E. and Long, C. 2006. Kinesio ${ }^{\circledR}$ taping in strok: improving functional use of the upper extremity in hemiplegia. Top strok rehabil topics in strok rehabilitation/summer. 13(3); Pp. 31-42.

14. Kase, K. Wallis, J. and Kase, T. 2003. Clinical therapeutic applications of the kinesio ${ }^{\circledR}$ taping method. 2 nd edition; Tokyo, Japan: Ken Ikai Co. Ltd. Pp. 2-3.

15. Hartoko, R. A., Andriana, R. A. M., \& Kusumawardani, M. K. (2017). Immediate Effect of Elastic Taping Application on Gait Functional Ability in Patients with Stroke. Science and Technology Publication, 337-343. https://doi.org/10.5220/0007321203370343

16. Kurnia YI, Subadi I, Pawana IPA, Wibisono S. The Influence of Elastic Taping on Dynamic Muscular Control (DynamicControl Ratio) Evertor-Invertor Ankle in Type 2 Diabetes Mellitus Male with Complications of Peripheral Neuropathy. SPMRJ.
2020;2(2):57-65

17. Bartels, E. and Bitterman, H.J. 2004. Transcranial Contrast Imaging of Cerebral Perfusion in Strok Patients Following Decompressive Craniectomy. Ultraschall in Med. 25: 206-213.

18. Huang, Y.C., Leong, C.P., Wang, L., Wan, L.Y., Yang, Y.C., Chuang, C.Y. and Hsin, Y.J. 2016. Effect of Kinesiology Taping on Hemiplegic Shoulder Pain and Functional Outcomes in Subacute Strok Patients: a Randomized Controlled Study. European Journal of Physical and Rehabilitation Medicine. 52 (6): 774-81.

19. Bohannon, R.W. and Andrews, A.W. 1989. Shoulder subluxation and pain in strok patients. American Journal of Occupational Therapy. Vol.44, No.6, Pp. 507-509.

20. Yang, L., Yang, J. and He, C. 2018. Clinical Study. The Effect of Kinesiology taping on the hemiplegic Shoulder Pain: A Randomized Controlled Trial. Journal of Healthcare Engineering. Cina. Pp. 1-5.

21. Chatterjee, S., Hayner, K.A., Arumugam, N., Goyal, M., Midha, D., Arora, A., Sharma, S. and Kumar, S.P. 2016. The California Tri-pull Taping Method in the Treatment of Shoulder Subluxation After Strok: A Randomized Clinical Trial. North American Journal of Medical Sciences. Published by Wolters Kluwer-Medknow. Vol. 8. Issue 4. Pp. 174181.

22. Chatterjee, S., Arumugam, N., Midha, D., Goyal, M., Arora, A., Sharma, S. and Kumar, S.P. 2015. Effect of California Tri-Pull Taping Method on Shoulder Subluxation, Pain, Active Range of Motion and Upper Limb Functional Recovery After Strok - A Pretest Post Test Design. American Journal of Psychiatry and Neuroscience. 3(5): 98-103. 
23. Pillastrini, P., Rocchi, G., Deserri, D., Foschi, P., Mardegan, M., Naldi, M.T., Villafane, J.H. and Bertozzi L. 2015. Effectiveness of neuromuscular taping on painful hemiplegic shoulder: a randomised clinical trial. Disabil Rehabil. 38: 1603-1609.

24. Heo, M.Y., Kim, C.Y. and Nam, C.W. 2015. Influence of the application of inelastic taping on shoulder subluxation and pain changes in acute strok patients. J Phys Ther Sci. 27: 3393-3395.

25. Lindgren, I., Jonsson, A.C., Norroving, B. and Lindgren, A. 2006. Shoulder pain After Strok. A Prospective Population-Based Study. Department of Neurology, Clinical Sciences, Lund University, Lund, Sweden. Pp. 344-347.

26. Kumbrink, B. 2012. K-Taping an illustrated guide. Springer-Verlag Berlin Heidelberg. Pp. 2-3.

27. Słupik, A., Dwornik, M., Białoszewski, D. and Zych, E. 2007. Effect of kinesio taping on bioelectrical activity of vastus medialis muscle. preliminary report. Ortop Traumatol Rehabil. 9: 644-651.

28. Bicici, S., Karatas, N. and Baltaci, G. 2012. Effect of athletic taping and kinesiotaping ${ }^{\circledR}$ on measurements of functional performance in basketball players with chronic inversion ankle sprains. Ankara-Turkey. The international journal of sports physical therapy. Vol. 7: No. 2: 154-155.

29. Huang, Y.C., Chen, P.C., Tso, H.H., Yang, Y.C., Ho, T.L. and Leong, C.P. 2019. Effects of Kinesiotaping on Hemiplegic Hand in Patients with Upper Limb Post-Strok Spasticity: A R Randomized Controlled Pilot Study. European Journal of Physical and Rehabilitation Medicine. Edizioni Minerva Medica. Pp. 3-17.

30. Sennfält, S., Norrving, B., Petersson, J.
And Ullberg, T. 2018. Long-Term Survival And Function After Strok. A Longitudinal Observational Study From The Swedish Strok Register. American Heart Association. Pp. 1-8.

31. Jerrgensen, H.S, Nakayama, H., Reith, J., Raaschou, H.O. And Olsen, T.S. 1996. Strok Recurrence: Predictors, Severity, And Prognosis. The Copenhagen Strok Study. Denmark.Pp. 891-895.

32. Olsen, T.S. 2009. Strok Recurrence And Prognosis After Strok. Chapter 21, Handbook Of Clinical Neurology, Vol. 92 (3rd Series), Strok, Part I. Denmark. Elsevier B.V. Pp. 407417.

33. Kim, K., Kim, Y.M. and Kim, E.K. 2014. Correlation Between The Activities Of Daily Living Of Strok Patients In A Community Setting And Their Quality Of Life. Korea. J. Phys. Ther. Sci. Vol. 26, No. 3, Pp. 417-419.

34. Kim, E.B. and Kim, Y.D. 2015. Effects of kinesiology taping on the upperextremity function and activities of daily living in patients with hemiplegia. J Phys Ther Sci. 27: 1455-1457.

35. Castro-Sanchez, A.M., Lara-Palomo, I.C., Mataran-Penarrocha, G.A., FernandezSanchez, M., Sanchez-Labraca, N. and Arroyo-Morales, M. 2012. Kinesio taping reduces disability and pain slightly in chronic non-specific low back pain: a randomized trial. J Physiother. 58: 89-95.

36. Griffin, A. and Bernhardt, J. 2006. Strapping the hemiplegic shoulder prevents development of pain during rehabilitation: a randomized controlled trial. Melbourne, Australia Clinical Rehabilitation. 20: 287-295. 